\title{
Nature Morte
}

\author{
Jim Hobbs
}

Nature Morte is a suite of $16 \mathrm{~mm}$ films composed of different floral arrangements, whereby the visual subject matter also transforms into a source of sound. Looking back towards Robert Mapplethorpe's early floral photographs, the film takes on board the ideas that the flowers represented here are simultaneously life and death humming with an intensified frequency. The focused and durational gaze for each "still life" explores the visual beauty of a staged composition, while at the same time searches for moments within the visual frame that are able to disrupt the optical soundtrack on the celluloid's surface. The resulting sounds are more akin to abstract noise that vary in intensity from scene to scene. The image becomes sound and the sound becomes image. Nature Morte has been exhibited in multiple formats including single channel screenings, live performances and sculptural installations. The following pages are yet another manifestation of the work, utilizing the format of a photoessay to dissect the piece through visual scans and time notations. One has the ability to experience the film in its totality as a singular image, while simultaneously freezing time in order to scrutinize each frame's granular elements which produce sound. 


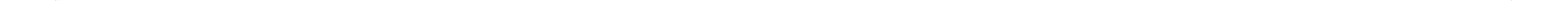


Gypsophila paniculata

Ornithogalum thyrsoides

Phalaenopsis

Lilium orientalis

Zantedeschia aethiopica

Tulipa gesneriana

Brassica 

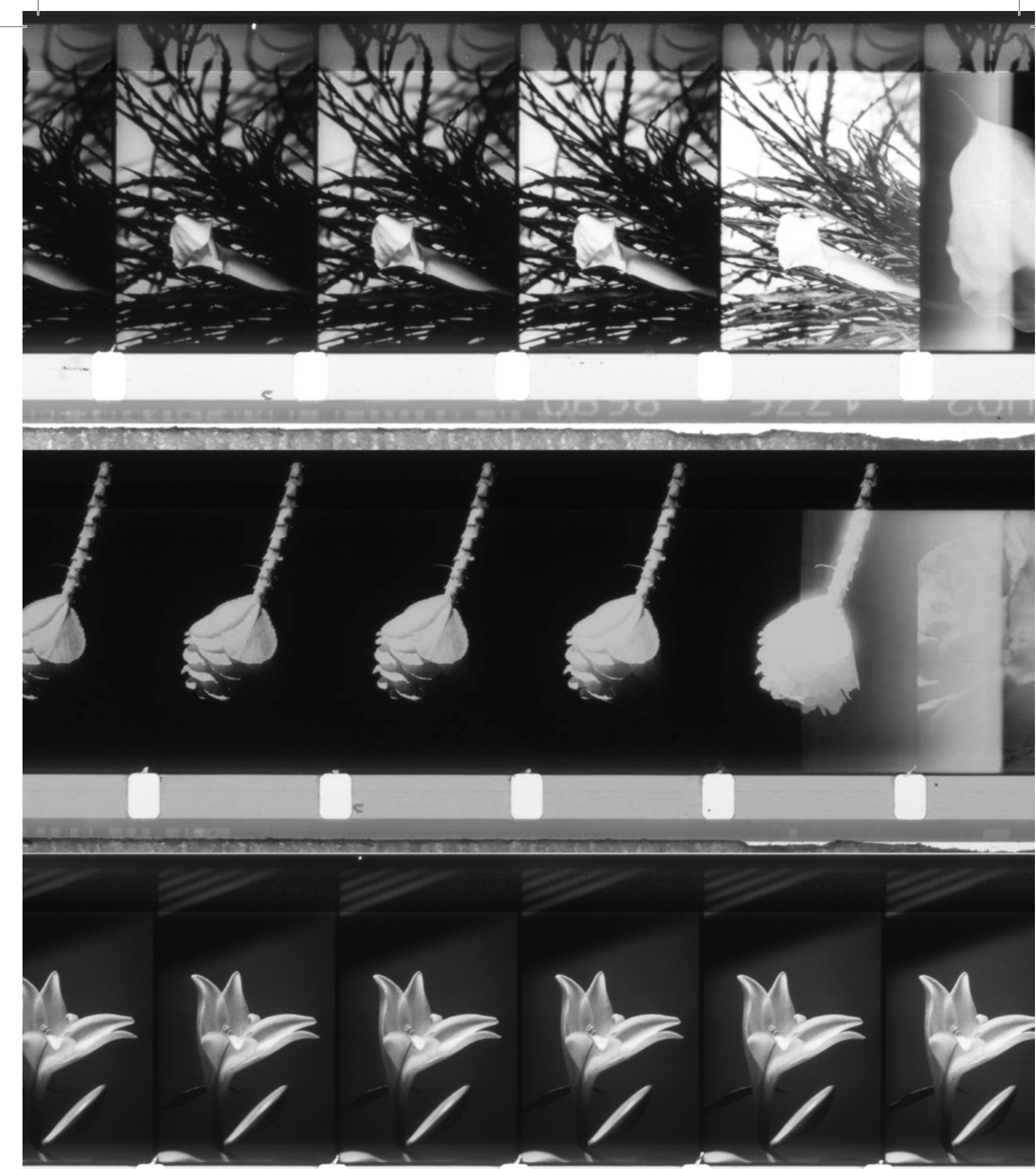
